DOI: $10.17805 /$ trudy.2018.1.2

\title{
ИЗУЧЕНИЕ ПРОБЛЕМЫ ПСИХИЧЕСКОГО ЗДОРОВЬЯ ДЕТЕЙ И ПОДРОСТКОВ В РАБОТАХ ПСИХОЛОГОВ МОСКОВСКОГО ГУМАНИТАРНОГО УНИВЕРСИТЕТА
}

\author{
Н. В. Гребенникова \\ Московский гуманитарный университет
}

\begin{abstract}
Аннотация: В статье представлены результаты психологических исследований, посвященных изучению эмоционально-личностной сферы детей и подростков с различными проблемами психического здоровья, а также в целом социальной ситуации их развития, которые проводились на факультете психологии Московского гуманитарного университета в последние годы.
\end{abstract}

Ключевые слова: психическое здоровье; личностная сфера; дети с ограниченными возможностями здоровья; дети-сироты; совладание; субъективные представления; аддиктивное поведение подростков; Московский гуманитарный университет

\section{STUDY INTO CHILDREN'S AND ADOLESCENTS' MENTAL HEALTH IN WORKS OF PSYCHOLOGISTS OF MOSCOW UNIVERSITY FOR THE HUMANITIES}

\author{
N. V. Grebennikova \\ Moscow University for the Humanities
}

\begin{abstract}
The article presents the results of the psychological research devoted to the study into the emotional and personal sphere of children and adolescents with different mental health problems, as well as the overall social situation of their development. This researches has been conducted at the Faculty of Psychology of Moscow University for the Humanities in recent years.

Keywords: mental health; personal sphere; children with disabilities; orphans; coping; subjective ideas; addictive behaviour of adolescents; Moscow University for the Humanities
\end{abstract}

Данная статья представляет собой обобщение материалов, полученных самим автором, а также результатов работ аспирантов, магистрантов и студентов, выполненных под его руководством в период с 1998 по 2017 гг. в русле научных исследований, проводимых сначала на кафедре психологии личности и педагогики (впоследствии - психологии развития и акмеологии), а затем кафедры общей психологии и истории психологии Московского гуманитарного университета.

Началом данного направления исследований послужили две кандидатские диссертации, посвященные одной из мало разработанных проблем психологии аномального развития - проблеме изучения особенностей эмоциональной сферы детей дошкольного и младшего школьного возраста с такими распространен- 
ными в настоящее время органическими поражениями центральной нервной системы, как детский церебральный паралич и гидроцефалия. Особое значение изучение данной категории детей имеет в связи с актуальной на сегодняшний день проблемой их адаптации к системе инклюзивного образования (Гурова, 2013, 2014; Гурова, Гребенникова, 2016). В диссертационном исследовании С. А. Стельмах (Стельмах, 1999) было показано, что основными характеристиками эмоциональной сферы детей с ДЦП являлись: наличие низкой психологической активности, склонность к пониженному настроению, легкая истощаемость, выраженность страхов и их неадекватность, раздражительность, увеличение уровня агрессивности с дисфорическими проявлениями, враждебностью, направленной против кого-либо, высокий уровень тревожности и ощущение постоянного напряжения. Оценка эмоциональной устойчивости и эмоционального реагирования, проведенная на больных и здоровых детях (Стельмах, Гребенникова, 1999), показала, что дети с ДЦП в большей мере уязвимы в отношении фрустрационных воздействий, они демонстрировали чрезмерную требовательность к окружающим и выраженную фиксацию на самозащите в отличие от детей контрольной группы, которые в ситуации фрустрации предпочитали эмоциональные реакции, направленные на разрешение ситуации.

Среди наиболее значимых факторов, влияющих на характер эмоциональных проявлений у детей с ДЦП данной возрастной группы, были выделены такие, как наличие лечебных процедур, степень выраженности двигательного дефекта и особенности стиля семейного воспитания.

Изучению эмоциональной сферы детей с гидроцефальным синдромом, обучающихся по общеобразовательным программам, посвящена диссертация Е. В. Щетининой (Щетинина, 2002). Автором было проведено систематическое исследование различных аспектов эмоциональной сферы детей данной группы, показавшее, что ее отличительными особенностями являются преобладание повышенного фона настроения в сочетании с тревожностью, высокая лабильность эмоциональных реакций, большое количеством страхов, наличие признаков агрессивного поведения, завышенная самооценка, трудности саморегуляции, негативное отношение к школьному обучению.

Изучение взаимосвязи особенностей эмоционально-личностной сферы детей с гидроцефальным синдромом и характера детско-родительских отношений выявило наличие корреляции наблюдаемой у детей эмоциональной возбудимости, гиперактивности, расторможенности с наличием эгоцентрического типа отношения родителей, а также их отношения по типу отвержения и гиперсоциализации. Специально проведенное исследование влияния таких факторов, как тяжесть и латерализация органического поражения мозга на эмоциональное состояние (Гребенникова, Щетинина, 2012) позволило сделать вывод о том, что в наибольшей степени проявление страхов и тревожности связано с одной стороны, со степенью поражения ЦНС, а с другой - с преимущественным поражением левого полушария мозга.

Другим часто встречающимся в детском возрасте расстройством психического здоровья, как известно, являются неврозы. Как показывают многочисленные исследования, наиболее частой причиной их возникновения является нали- 
чие противоречия или несоответствия между потребностями и возможностями их непосредственного удовлетворения. Однако эти условия приводят к неврозу только тогда, когда данное противоречие продуктивно не разрешается и человек не может найти адекватного способа совладания с трудными жизненными ситуациям (Одинцова, Баринова, Гурова, 2017).

Проблеме преодоления младшими школьниками трудных жизненных ситуаций было посвящено диссертационное исследование и последующие работы Е. Г. Сурковой (Суркова, 2004; Суркова, Гребенникова, 2011). Автором было показано, что в наибольшей степени на процесс адаптации к повседневным перегрузкам у младших школьников влияют особенности их эмоционально-личностной сферы. В исследовании было получено, что дети с низким уровнем адаптации характеризуются более высоким уровнем тревожности, чувством неполноценности, они более агрессивны, чаще имеют трудности в общении по сравнению с хорошо адаптированными сверстниками. Более сложной оказалась зависимость успешности преодоления трудных жизненных ситуаций от самооценки, которая в свою очередь зависела от половой принадлежности: успешность адаптации у мальчиков была связана с высоким уровнем самооценки, а у девочек - со степенью ее адекватности.

Оказалось, что не только личностные особенности, но и когнитивные способности детей влияют на успешность адаптации к повседневным микрострессорам. Высокий уровень продуктивности и оригинальности мышления положительно влияет на адаптацию к повседневным перегрузкам у девочек и отрицательно - y мальчиков. Высокий уровень практического интеллекта в целом положительно влияет на способность к преодолению жизненных трудностей у младших школьников, но такое влияние в большей степени выражено у девочек.

В целом исследование Е. Г. Сурковой позволило считать доказанным положение о том, что существуют значительные различия в стратегиях преодоления повседневных трудных жизненных ситуаций у девочек и мальчиков, обусловленные их психологическими особенностями. Успешная стратегия мальчиков строится на высокой самооценке, способности рассчитывать на собственные силы при разрешении проблемных ситуаций, использовании стереотипных и более агрессивных способов их разрешения. Успешные стратегии девочек содержат в своей основе более адекватную самооценку, включают в себя более творческий подход к выбору способов преодоления трудной жизненной ситуации и характеризуются большей значимостью коммуникативного фактора.

Разработка проблемы психического здоровья детей и подростков осуществлялось также в рамках изучения личностного самоопределения детей-сирот (Гребенникова, 2006, 2007; Гребенникова, Федотова, 2006; Носкова, Гребенникова, 2008). Известно большое число психологических исследований, выявляющих значительные изменения познавательных процессов и личностных свойств воспитанников детских домов и интернатов, приводящих к проблемам их социальной адаптации. Поэтому исследование развития личности детей, воспитывающихся в детском доме, является не только очень острой проблемой современного общества, имеющей практическое значение, но и представляет большой научный 
интерес. Особый раздел данной проблемы был связан с изучением особенностей мотивационно-личностной сферы у подростков-сирот, воспитывающихся в государственных учреждениях.

При анализе результатов изучения личностной сферы подростков-сирот и их сверстников, воспитывающихся в семьях (Гребенникова, 2006) было получено, что испытуемым обеих групп были свойственны неуверенность в себе и трудности общения с другими людьми. При этом показатели враждебности, конфликтности, чувства неполноценности, тревожности и депрессии были достоверно выше в экспериментальной группе, а показатели незащищенности - в контрольной Также было показано, что подростки, живущие в семьях, обнаруживают зависимость от родителей, неуверенность в своих силах, потребность в опеке и безопасности. Подросткам-сиротам, наоборот, свойственны явно преувеличенное стремление к независимости, высокая уверенность в своих силах и возможностях. Они бессознательно наделяют себя такими качествами, которые присущи сильному, уверенному в себе человеку, в реальности же они являются достаточно пассивными, инфантильными личностями с заниженной самооценкой и комплексами неполноценности.

Сравнительный анализ особенностей смысло-жизненных ориентаций подростков (Гребенникова, 2007) показал, что подростки, имеющие родительские семьи, продемонстрировали высокую ориентацию на учебную деятельность, которая оценивается ими как способ дальнейшей реализации их жизненных планов. В отличие от них подростки из детских домов не имеют четкого жизненного плана и конкретно сформированных жизненных целей, учебная и профессиональная деятельность не являются для них ведущими, они живут сегодняшним днем и уверены в том, что единственный смысл жизни состоит в том, чтобы просто жить.

О состоянии душевного здоровья детей-сирот также можно было судить, исследуя их мотивационно-потребностную сферу через анализ внутренних конфликтов, понимаемых как значительное расхождение между «ценностью» и «доступностью» в различных жизненных сферах. По результатам исследования особенностей внутриличностных конфликтов у воспитанников интернатных учреждений (Гребенникова, Кузина, Федотова, Суркова, 2007) можно было заключить, что у детей-сирот на фоне общей удовлетворенности текущей жизненной ситуацией отмечается более высокий, по сравнению с детьми из семей, уровень дезинтеграции в мотивационно-личностной сфере. Показано также, что к труднодостижимым сферами жизни для детей-сирот можно отнести те, которые связаны, прежде всего, с обеспечением материальной стороны жизни, а также с независимостью и самостоятельностью. При этом собственно внутриличностные конфликты, сопровождающиеся сильными эмоциональными переживаниями, выражены только в такой сфере, как счастливая семейная жизнь. Значительное снижение мотивации у воспитанников интерната выявлялось в жизненных сферах, связанных с активной, деятельной жизнью, красотой природы и искусства, познанием и творчеством.

Одним из показателей психического здоровья, как известно, является наличие у человека жизненной перспективы, умение выстроить временной план собственных действий. Изучение представлений о жизненных перспективах 
детей-сирот составляет содержание диссертационного исследования Н. И. Федотовой (Федотова, 2007, 2008). На примере образовательных учреждений различного типа (детский дом и интернат) автору удалось показать, что ситуация отрыва ребенка от семьи и помещение его в детский дом или интернат приводит к определенной деформации различных компонентов представлений о будущем у подростков. Исследование показало, что «специфика планирования ближней, средней и дальней перспективы у детей-сирот опосредуется особенностями ценностных ориентаций и отражает тревожность и пессимизм относительно событий ближайшего года, ожидание нестабильности, пустоты и в то же время активности в предстоящем пятилетии и необычность отдаленного будущего, инициируемого другими» (Федотова, 2008: 180).

В данном исследовании специально изучались межфункциональные изменения ценностно-смысловой, эмоциональной и когнитивной составляющих представлений о жизненных перспективах детей-сирот. По данным Н. И. Федотовой, ценности, которые презентируют профессиональную самореализацию, здоровье, эстетические переживания, обучение в школе, а также события раннего детства у детей-сирот связаны с негативным восприятием будущего. Положительное эмоциональное отношение к будущему ассоциируется у них с такими ценностями, как материальное и семейное благополучие, наличие хороших и верных друзей, независимость и, свобода, при этом повышение значимости семьи для положительного восприятия будущего более характерно для детей из детского дома, а стремление к независимости и самостоятельной жизни - для воспитанников интерната. Стремление к счастливой семейной жизни, работа, обучение в колледже лежат в основе насыщения будущего важными событиями у воспитанников детских домов и интернатов, тогда как у их сверстников, воспитывающихся в семье - уверенность в себе и самореализация в профессиональной сфере. Согласно Н.И.Федотовой «оказалось, что, чем более насыщенным представляется будущее подросткам, лишенным родительского попечения, тем более тяжелым оно воспринимается. Как в экспериментальной, так и в контрольной группе положительное эмоциональное отношение к будущему опосредовано удовлетворенностью пройденным этапом жизни» (там же: 179).

Нередко в психологической литературе отмечается тот факт, что выпускники детских домов и интернатов испытывают большие сложности в создании собственной семьи и построении межличностных отношений внутри нее. В ходе изучения темы, связанной с жизненными перспективами детей-сирот, также исследовались их представления о своей будущей семье (Гребенникова, Федотова, 2010). Согласно полученным результатам, подростки, воспитывающиеся в сиротских учреждениях, считают семейную жизнь важной ценностью для построения своего будущего, при этом у многих из них имеет место уверенность в невозможности ее достижения. Также в отличие от своих сверстников из семей, которых в большей степени волнуют вопросы, связанные с образованием и карьерой, для подростков-сирот создание собственной семьи в будущем побуждается, как правило, мотивами получения той любви, которая не была получена ими от собственных родителей.

Не менее важным вопросом, связанным с проблемой психического здоровья 
детей и подростков, является психологическое изучение семей, воспитывающих детей с ограниченными возможностями здоровья. Как правило, рождение ребенка с отклонениями в развитии воспринимается его родителями как величайшая трагедия. Факт появления на свет ребенка «не такого, как у всех», является причиной сильного стресса, испытываемого родителями, в первую очередь матерью. Стресс, имеющий пролонгированный характер, оказывает сильное деформирующее воздействие на психику родителей и становится исходным условием резкого травмирующего изменения сформировавшегося в семье жизненного уклада.

Проведенное исследование, направленное на изучение психологических характеристик матерей, воспитывающих детей с синдромом Дауна (Гребенникова, Щербакова, 2012), показало, что большую часть выборки (50\%) составили женщины, относящиеся к так называемому «психосоматическому» типу, для которого свойственно подавление фрустрации, связанной с рождением больного ребенка, и ее конверсия в психосоматические проявления. «Авторитарный» и «невротический» типы личности были выявлены у $35 \%$ и $15 \%$ матерей соответственно. Анализ эмпирических данных, полученных при обследовании матерей детей с фенилкетонурией (Буренина, 2017а: Электр. ресурс), показал, что при наличии высоких показателей по всем личностным факторам опросника «большая пятерка», значения привязанности и самоконтроля у них оказались достоверно ниже, чем у матерей здоровых детей. Также у них отмечалось общее снижение смысложизненных ориентаций.

Выявлены достоверные различия в типах отношений матерей к детям в семьях со здоровыми детьми и детьми с синдромом Дауна. В обеих группах матерей отмечается тенденция не использовать активно запреты и наказания. При этом в семьях с больным ребенком достоверно большее число матерей стремится к отношениям по типу «гиперпротекция» и «фобия утраты ребенка».

Проведенный корреляционный анализ выявил следующие взаимосвязи личностных характеристик матерей, воспитывающих детей с синдромом Дауна, и типов ее отношения к ребенку. Выяснено, что чем больше подавляется фрустрация, связанная с болезнью ребенка, тем в большей степени матери потворствуют ребенку, «балуют его». Матери, для которых характерна тревожность в сочетании с мнительностью и нерешительностью (невротический тип), чаще демонстрируют неустойчивый тип отношения к ребенку, который выражается как в потворствовании ему, с одной стороны, так и в жестоком обращении с ним - с другой. Также у матерей невротического типа преобладает минимальность санкций в отношении к ребенку, связанная с их пассивной личностной позицией. У матерей, склонных к депрессии, проявлениям враждебности, дисфории и аффекта, выявляются проявления жестокого обращения с ребенком и игнорирование его потребностей (Гребенникова, Щербакова, 2012).

В русле данного направления исследований была подготовлена магистерская диссертация С. М. Бурениной (Буренина, 2017b) посвященная изучению особенностей совладающего поведения матерей, имеющих детей с ограниченными возможностями здоровья. По данным автора, матери детей с ограниченными возможностями здоровья и матери здоровых детей применяют схожие стратегии для преодоления проблемных ситуаций. Женщинам обеих групп свойственны 
в качестве основных копинг-стратегий планирование решения проблемы, поиск социальной поддержки и положительная переоценка. Также матерями обеих групп активно используются стратегии «самоконтроль» и «принятие ответственности». Выявленные различия позволили констатировать большую выраженность стратегии «планирование решения проблем» у матерей больных детей.

Как отмечается в исследовании С. М. Бурениной, значительно большее количество достоверных различий выявлено между экспериментальной и контрольной группами при анализе типов психологических защит. Так, если в экспериментальной группе основным механизмом защиты является отрицание, то матери контрольной группы чаще прибегают к такому механизму защиты, как интеллектуализация. Статистически значимые различия были выявлены при сравнении показателей общей напряженности психологических защит, а также для «отрицания», «регрессии», «проекции», «замещения» в сторону их увеличения у матерей детей с ограниченными возможностями здоровья.

С. М. Буренина предполагает, что описанные ею различия в использовании совладающего поведения, могут быть обусловлены глубокой травматизацией матерей, имеющих больных детей, психогенным воздействием длительного стресса, связанного с болезнью ребенка, большими психическими затратами и внутренним напряжением. Хронический характер негативных переживаний с ежедневными, не исчезающими трудностями обусловливает выраженность и иерархию защитных механизмов у матерей больных детей. Таким образом, психологическое исследование совладающего поведения матерей детей с ограниченными возможностями здоровья показало, что если на осознанном уровне эти механизмы практически такие же, как у матерей здоровых детей, то на бессознательном уровне они значительно разнятся.

Анализ связей между личностными особенностями матерей больных детей и характером совладающего поведения позволил высказать автору предположение о том, что матери здоровых детей в случае трудной жизненной ситуации ищут опору во вне, тогда как матери больных детей - как во вне, так и внутри собственной л

В проводимых на кафедре психологических исследованиях особое внимание уделялось также изучению личностных особенностей подростков, склонных к различным видам аддиктивного поведения. В работе Н. В. Гребенниковой (Гребенникова, 2013) были определены следующие личностные качества, доминирующие в группе подростков, склонных к употреблению психоактивных веществ: слабость «Я», проявляющаяся в беспечности, безрассудности в выборе партнеров по общению, ведомости в общественных контактах и поиске социального одобрения в группе; излишняя замкнутость и необщительность (пренебрежение общественными нормами ради своих собственных интересов, пониженный фон настроения); состояние фрустрированности, обусловленное неудовлетворенностью достижениями и положением подростка в социально значимом окружении.

Исследование старших подростков в контексте проблемы зависимости от компьютерных игр (Гребенникова, 2017: Электр. ресурс) позволило сделать выводы о том, что наиболее частыми мотивами вовлечения старшеклассников в компьютерные игры, являются желание расслабиться, испытать возбуждение, 
почувствовать себя победителем, и в наименьшей степени - уйти от реальности. Изучение взаимосвязи характерологических особенностей подростков и степени выраженности склонности к компьютерно-игровой зависимости позволили высказать предположение о том, что данный вид аддикции выражен в большей степени у тех подростков, у которых имеют место такие акцентуации характера, как гипертимность, эмотивность, тревожность и возбудимость.

В целом, подводя итоги проведенным исследованиям психологов Московского гуманитарного университета, можно сказать, что полученные в них результаты относительно особенностей эмоционально-личностной сферы детей и подростков с ограниченными возможностями здоровья, различными видами отклоняющегося поведения, а также анализ различных аспектов их социальной ситуации развития дополняют наши представления о современном состоянии психического здоровья наших детей.

\section{СПИСОК ЛИТЕРАТУРЫ}

Буренина, С. М. (2017а) Совладающее поведение матерей, воспитывающих детей с диагнозом фенилкетонурия [Электронный ресурс] // Научные труды Московского гуманитарного университета. № 1. C. 46-52. URL: http://journals. mosgu.ru/trudy/article/view/398 (дата обращения: 11.01.2018). DOI: 10.17805/ trudy.2017.1.7

Буренина, С. М. (2017b) Особенности совладающего поведения матерей, имеющих детей с врожденными аномалиями здоровья : магистерская диссертация (рукопись). М. : МосГУ. 90 с.

Гребенникова, Н. В. (2006) Ценностные ориентации подростков, воспитывающихся в сиротских учреждениях // Материалы межрегиональной конференции «Подготовка воспитанников учреждений для детей-сирот, оставшихся без попечения родителей, к самостоятельной жизни и межведомственное взаимодействие по поддержке выпускников» М. : Министерство образования и науки РФ. C. 50-66.

Гребенникова, Н. В., Федотова, Н. И. (2006) Особенности жизненных перспектив воспитанников детского дома // Психология перед вызовом будущего. Материалы научной конференции, приуроченной к 40-летнему юбилею факультета психологии МГУ. М. : МГУ. С. 274-275.

Гребенникова, Н. В. (2007) Особенности ценностно-смысловой сферы подростков, оставшихся без попечения родителей // Личностное и профессиональное самоопределение детей-сирот и детей, оставшихся без попечения родителей. М. : МосГУ. С. 39-55.

Гребенникова, Н. В., Кузина, Ю. А., Федотова, Н. И., Суркова, Е. Г. (2007) Внутриличностные конфликты подростков, воспитывающихся в интернатных учреждениях // Личностное и профессиональное самоопределение детей-сирот и детей, оставшихся без попечения родителей. М. : МосГУ. С. 22-39.

Гребенникова, Н. В., Федотова Н. И. (2010) Особенности представлений о своей будущей семье у детей-сирот // Современная российская семья: традиции и альтернативы : сборник научных статей Всероссийской научно-практической конференции. Муром : Изд-во МПСИ. С. 134-139. 
Гребенникова, Н. В., Щербакова, Е. А. (2012) Особенности детско-родительских отношений в семьях, воспитывающих детей с синдромом Дауна // Российская семья: прошлое, настоящее, будущее : сборник статей. Муром : Изд-во МПСИ. C. 40-46.

Гребенникова, Н. В., Щетинина, Е. В. (2012) Особенности эмоционально-личностной сферы у детей с гидроцефалией // Нейропсихология в диагностике, коррекции, консультировании и профилактике нарушений здоровья человека материалы Всероссийской научно-практической конференции (Барнаул, 18-20 апреля 2011 г.). / редкол.: Л. Д. Демина, Д. В. Труевцев. Барнаул. С. 16-23.

Гребенникова, Н. В. (2013) Особенности личности подростков с риском возникновения химической зависимости // Актуальные проблемы психологических исследований. М. : МосГУ. С. 5-11.

Гребенникова, Н. В. (2017) Характерологические особенности старших подростков, склонных к компьютерно-игровой зависимости [Электронный ресурс] // Научные труды Московского гуманитарного университета. № 3. C. 56-66. URL: http://journals.mosgu.ru/trudy/article/view/498 (дата обращения: 11.01.2018). DOI: $10.17805 /$ trudy.2017.3.4

Гурова, Е. В. (2013) К вопросу о повышении информационно-коммуникативной компетенции преподавателей дистанционного обучения // Психологическая помощь социально незащищенным лицам с использованием дистанционных технологий (интернет-консультирование и дистанционное обучение). Материалы III Международной научно-практической конференции / под ред. Б. Б. Айсмонтаса, В. Ю. Меновщикова. М. : МГППУ. С. 180-183.

Гурова, Е. В. (2014) Проблема психологической готовности преподавателя ВУЗа к взаимодействию со студентами с ограниченными возможностями здоровья // Психологическая помощь социально незащищенным лицам с использованием дистанционных технологий (интернет-консультирование и дистанционное обучение). Тезисы и статьи участников IV Международной научно-практической конференции / под ред. Б. Б. Айсмонтаса, В. Ю. Меновщикова. М. : МГППУ. С. 327-333.

Гурова, Е. В., Гребенникова, Н. В. (2016) Инклюзия в вузе: проблема готовности преподавателей // Высшее образование для XXI века: XIII Международная научная конференция. Москва, 8-10 декабря 2016 г.: Доклады и материалы. Секция 4. Психологические проблемы образования / отв. ред. А. Л. Журавлев. М. : Издво Моск. гуманит. ун-та. 111 с. С. 45-49.

Носкова, О. Г., Гребенникова, Н. В. (2008) Об итогах работы по теме «Особенности личностного и профессионального самоопределения детей-сирот, воспитывающихся в государственных учреждениях, в контексте современной социально-культурной ситуации в стране» // Психологическая помощь детям-сиротам в личностном и профессиональном самоопределении. Вып. 1. М. : МосГУ. С. 5-13.

Одинцова, М. А., Баринова, О. В., Гурова, Е. В. (2017) Копинг-стратегии преодоления и жизнестойкость людей с разным уровнем эмоционального интеллекта // Вестник Полоцкого государственного университета. Серия Е: Педагогические науки. № 7. С. 75-80.

Стельмах, С. А. (1999) Особенности эмоциональной сферы детей с детским церебральным параличом дошкольного и младшего школьного возраста : авто- 
реф. ... канд. психол. н. М. 19 с.

Стельмах, С. А., Гребенникова, Н. В. (1999) Использование теста С. Розенцвейга для исследования особенностей эмоциональной сферы детей с детским церебральным параличом // Состояние и проблемы измерений 6-я всероссийская научно-техническая конференция. С. 330-331. С. 330.

Суркова, Е. Г. (2004) Преодоление трудных жизненных ситуаций младшими школьниками : дисс. ... канд. психол. н. М. 167 с.

Суркова, Е. Г., Гребенникова, Н. В. (2011) Адаптация к повседневным перегрузкам у младших школьников // Вестник РУДН (психология, педагогика). № 2. С. 39-47.

Федотова, Н. И. (2007) Особенности субъективных представлений о времени собственной жизни у воспитанников школы-интерната» // Знание. Понимание. Умение. № 4. С. 221-227.

Федотова, Н. И. (2008) Представления о жизненных перспективах детей-сирот (на примере образовательных учреждений различного типа) : дисс. ... канд. псих. н. М. 208 с.

Щетинина, Е. В. (2002) Особенности эмоциональной сферы детей с проблемами психического развития : дисс. ... канд. психол. н. М. 276 с.

Дата поступления: 20.02.2018 г.

Гребенникова Наталия Васильевна - кандидат психологических наук, доцент, профессор кафедры общей психологии и истории психологии Московского гуманитарного университета. Адрес: 111395, Россия, г. Москва, ул. Юности, д. 5. Тел.: +7 (499) 374-67-20. Эл. адрес: grebennikovanataliya@yandex.ru

Grebennikova Natalia Vasilievna, Candidate of Psychology, Professor, Department of General Psychology and the History of Psychology, Moscow University for the Humanities. Postal address: 5, Yunosti St., Moscow, Russian Federation 111395. Tel.: +7 (499) 374-67-20. E-mail: grebennikovanataliya@yandex.ru

\section{Для цитирования:}

Гребенникова Н. В. Изучение проблемы психического здоровья детей и подростков в работах психологов Московского гуманитарного университета [Электронный ресурс] // Научные труды Московского гуманитарного университета. 2018. № 1. URL: http:// journals.mosgu.ru/trudy/article/view/677 (дата обращения: дд.мм.гг.). DOI: 10.17805/ trudy.2018.1.2 